\title{
Depression and metabolism: linking changes in leptin and ghrelin to mood \\ Michael Lutter ${ }^{1 *}$ and Joel Elmquist ${ }^{2}$
}

\author{
Addresses: ${ }^{1}$ Department of Psychiatry, University of Texas Southwestern Medical Center, 5323 Harry Hines Boulevard, Dallas, TX 75390-9127, USA; \\ ${ }^{2}$ Department of Internal Medicine, Division of Hypothalamic Research, University of Texas Southwestern Medical Center, 5323 Harry Hines \\ Boulevard, Dallas, TX 75390, USA \\ *Corresponding author: Michael Lutter (michael.lutter@utsouthwestern.edu) \\ FI000 Biology Reports 2009, I:63 (doi:10.34I0/BI-63)
}

The electronic version of this article is the complete one and can be found at: http://FI000.com/Reports/Biology/content/I/63

\begin{abstract}
Major depressive disorder is associated with an elevated risk of numerous metabolic disturbances, including obesity, metabolic syndrome, insulin-dependent diabetes mellitus type II, and death after myocardial infarction. Several recent papers also indicate that disturbances of mood may alter peripheral signaling pathways that regulate metabolic processes, including those involving leptin and ghrelin.
\end{abstract}

\section{Introduction and context}

The prevalence of obesity and associated disorders, including diabetes mellitus type II (DMII) and coronary artery disease, has dramatically risen in recent years. Obesity is quickly approaching tobacco use as the leading cause of preventable death in the US [1]. A growing body of literature indicates that obesity and metabolic disorders develop from a complex interplay between genetic susceptibility and environmental factors. Of the known causes, psychological stress is now thought to be an important environmental risk factor. For example, in New Zealand, a longitudinal study of 1,037 children found that girls who suffered from major depression in late adolescence had a 2.3-fold increased risk of obesity later in adulthood [2]. In addition to increasing the risk of becoming obese, major depressive disorder (MDD) is frequently associated with other comorbidities, including the metabolic syndrome, atherosclerosis, and diabetes.

While the occurrence of MDD after myocardial infarction (MI) has long been appreciated as a leading risk factor for post-MI mortality, the causal factor of the association is not clear [3]. Two large trials, SADHART (Sertraline AntiDepressant Heart Attack Trial) and ENRICHD (ENhancing Recovery in Coronary Heart Disease), attempted to determine the effect of treating post-MI MDD with medication and psychotherapy, respectively. While both treatment options were deemed to be safe and effective for the treatment of MDD in cardiac patients, the studies were underpowered to identify a mortality benefit. Thus, it is unclear whether the presence of MDD itself worsened cardiac outcome or whether MDD was more likely to occur in patients destined for negative outcomes [4].

Finally, many researchers have examined the complex association of MDD and DMII. Ali and colleagues [5] performed a meta-analysis of 10 studies that included over 51,000 patients and found higher rates of MDD in patients with diabetes than in patients without diabetes. In an attempt to determine the direction of association between MDD and DMII, Golden and colleagues [6] performed a large bidirectional study. The authors reported that, in patients without a diagnosis of diabetes at baseline, the presence of depressive symptoms slightly increased the risk of later developing diabetes after 3.2 years. Importantly, they also reported that the reverse association was true: a diagnosis of DMII increased the risk of having depressive symptoms at follow-up 3.1 years later. This study suggests a bidirectional association between mood disorders and diabetes, with the presence 
of one increasing the risk of developing the other. Despite the clear link between MDD and metabolic disorders in epidemiologic studies, relatively little is known about the mechanism that underlies this association [7]. Recent results have begun to inform us of the mechanism of this mind-body connection.

\section{Major recent advances}

Leptin, a hormone produced by adipose tissue, is well known for regulating food intake and body weight [8]. Recently, Lu and colleagues [9] proposed a role for leptin action in mood regulation. They reported a reduction in leptin levels after chronic unpredictable stress (CUS), a rodent model of stress-induced anhedonia. Furthermore, acute administration of leptin reversed the deficits observed in sucrose preference after CUS. Finally, in the forced swim test, a model of behavioral despair in rodents, leptin administration into the hippocampus caused an antidepressant-like effect.

Other recent studies suggest a potential role for leptin in mediating reward processing via direct action on the dopamine neurons of the ventral tegmental area (VTA). For example, Fulton and colleagues [10] reported that leptin deficiency blunted the locomotor response of mice to amphetamine injection. Dopamine levels as well as electrically stimulated dopamine release were also lower in leptin-deficient mice. In addition, Hommel and colleagues [11] demonstrated that direct infusion of leptin into the VTA suppresses feeding, while reduction of leptin receptor levels in the VTA by small interfering RNA increases food intake and locomotor activity.

Recently, our group suggested a potential role for ghrelin, a stomach-derived proappetite hormone, in the regulation of stress-induced changes in feeding and behavior [12]. Chronic social defeat stress (CSDS) is a preclinical model of chronic stress that models features of certain psychiatric disorders, including MDD, social anxiety, and post-traumatic stress disorder $[13,14]$. Following exposure to CSDS, mice display persisting deficits in social interaction as well as increased food consumption. During the same time frame, ghrelin levels increase and remain elevated for up to 1 month after the last stressor. Notably, mice lacking the ghrelin receptor exhibit reduced hyperphagia compared with wild-type mice exposed to social stress. However, growth hormone secretagogue receptor (GHSR)-null mice displayed worsened social isolation after CSDS, indicating that ghrelin signaling may be involved in distinct adaptations to stress. Finally, peripheral administration of ghrelin to wild-type mice produced anxiolytic-like and antidepressant-like responses in the elevated plus maze and the forced swim test.
The site of ghrelin action on mood is of considerable interest. Like leptin signaling, ghrelin signaling is thought to occur in the hippocampus and the VTA, two key areas regulating mood and reward. Diano and colleagues [15] reported that ghrelin signaling improves memory and spatial learning by increasing dendritic spine synapse density and long-term potentiation. Abizaid and colleagues [16] reported that ghrelin signaling in the VTA increased dopamine neuron activity and promoted feeding. Infusion of a ghrelin receptor antagonist directly into the VTA also inhibited the effect of peripheral administration of ghrelin on feeding, indicating that the VTA is a key target of ghrelinmediated food intake.

\section{Future directions}

Metabolic diseases are frequently comorbid with mental illness, although the mechanism of this association is unknown. Recent research using preclinical models of stress has revealed an unexpected role for the peripheral hormones leptin and ghrelin in the regulation of mood symptoms. These findings now suggest a possible mechanism linking metabolic dysregulation and chronic stress. Future studies will need to determine whether a stress-induced decrease in leptin and increase in ghrelin signaling contribute to the development of obesity, diabetes, metabolic syndrome, and coronary heart disease. Furthermore, the neuronal targets of leptin and ghrelin action on mood need to be elucidated. Preliminary work indicates that the hippocampus and VTA may be key targets for their action, although this hypothesis must be confirmed by direct genetic targeting of leptin and ghrelin receptor signaling in these specific neurons.

\section{Abbreviations}

CSDS, chronic social defeat stress; CUS, chronic unpredictable stress; DMII, diabetes mellitus type II; ENRICHD, ENhancing Recovery in Coronary Heart Disease; GHSR, growth hormone secretagogue receptor; MDD, major depressive disorder; MI, myocardial infarction; SADHART, Sertraline AntiDepressant Heart Attack Trial; VTA, ventral tegmental area.

\section{Competing interests}

The authors declare that they have no competing interests.

\section{Acknowledgements}

The authors would like to acknowledge the following for their financial support: National Institutes of Health (NIH) grants K08 MH084058-1A1, RL1 DK081182, RL1 DK081185, the NARSAD Young Investigator Award, and the Disease-Oriented Clinical Scholars Program from UT Southwestern. 


\section{References}

I. Danaei G, Ding EL, Mozaffarian D, Taylor B, Rehm J, Murray Cl, Ezzati $M$ : The preventable causes of death in the United States: comparative risk assessment of dietary, lifestyle, and metabolic risk factors. PLoS Med 2009, 6:e 000058.

2. Richardson LP, Davis R, Poulton R, McCauley E, Moffitt TE, Caspi A, Connell F: A longitudinal evaluation of adolescent depression and adult obesity. Arch Pediatr Adolesc Med 2003, I 57:739-45.

3. Plante GE: Depression and cardiovascular disease: a reciprocal relationship. Metabolism 2005, 54(5 Suppl I):45-8.

4. Joynt KE, O'Connor CM: Lessons from SADHART, ENRICHD, and other trials. Psychosom Med 2005, 67(Suppl I):S63-6.

5. Ali S, Stone MA, Peters JL, Davies MJ, Khunti K: The prevalence of comorbid depression in adults with Type 2 diabetes: a systematic review and meta-analysis. Diabet Med 2006, 23: I I65-73.

6. Golden SH, Lazo M, Carnethon M, Bertoni AG, Schreiner PJ, Diez Roux AV, Lee HB, Lyketsos C: Examining a bidirectional association between depressive symptoms and diabetes. JAMA 2008, 299:275I-9.

FI000 Factor 6.0 Must Read

Evaluated by Antonio Campayo 16 Sept 2008

7. Kishi T, Elmquist JK: Body weight is regulated by the brain: a link between feeding and emotion. Mol Psychiatry 2005, 10: 132-46.

8. Friedman JM: Leptin at $\mathbf{1 4}$ y of age: an ongoing story. Am J Clin Nutr 2009, 89:973S-9S.

9. Lu XY, Kim CS, Frazer A, Zhang W: Leptin: a potential novel antidepressant. Proc Natl Acad Sci U S A 2006, 103:1593-8.

10. Fulton S, Pissios P, Manchon RP, Stiles L, Frank L, Pothos EN, MaratosFlier $E$, Flier JS: Leptin regulation of the mesoaccumbens dopamine pathway. Neuron 2006, 5 I:8I I-22.

FI000 Factor 4.8 Must Read

Evaluated by Claire-Dominique Walker 17 Nov 2006, Sadaf Farooqi 06 Feb 2007
II. Hommel JD, Trinko R, Sears RM, Georgescu D, Liu ZW, Gao XB, Thurmon JJ, Marinelli M, DiLeone RJ: Leptin receptor signaling in midbrain dopamine neurons regulates feeding. Neuron 2006, 5I:80I-I0.

FI000 Factor 4.8 Must Read

Evaluated by Kent Berridge 27 Nov 2006, Claire-Dominique Walker OI Dec 2006, Laurence Tecott II Jan 2007

12. Lutter M, Sakata I, Osborne-Lawrence S, Rovinsky SA, Anderson JG, Jung S, Birnbaum S, Yanagisawa M, Elmquist JK, Nestler EJ, Zigman JM: The orexigenic hormone ghrelin defends against depressive symptoms of chronic stress. Nat Neurosci 2008, I I:752-3.

13. Avgustinovich DF, Gorbach OV, Kudryavtseva NN: Comparative analysis of anxiety-like behavior in partition and plus-maze tests after agonistic interactions in mice. Physiol Behav 1997, 61:37-43.

14. Krishnan $\mathrm{V}$, Berton $\mathrm{O}$, Nestler $\mathrm{E}$ : The use of animal models in psychiatric research and treatment. Am J Psychiatry 2008, 165:1109.

15. Diano S, Farr SA, Benoit SC, McNay EC, da Silva I, Horvath B, Gaskin FS, Nonaka N, Jaeger LB, Banks WA, Morley JE, Pinto S, Sherwin RS, Xu L, Yamada KA, Sleeman MW, Tschöp MH, Horvath TL: Ghrelin controls hippocampal spine synapse density and memory performance. Nat Neurosci 2006, 9:38I-8.

FI000 Factor 4.8 Must Read

Evaluated by Laurence H Tecott 28 Apr 2006, Tallie Baram 29 Aug 2006

16. Abizaid A, Liu ZW, Andrews ZB, Shanabrough M, Borok E, Elsworth JD, Roth RH, Sleeman MW, Picciotto MR, Tschöp MH, Gao XB, Horvath TL: Ghrelin modulates the activity and synaptic input organization of midbrain dopamine neurons while promoting appetite. J Clin Invest 2006, I 16:3229-39.

FI000 Factor 6.0 Must Read

Evaluated by Stephen Woods 24 Oct 2006 